\title{
Leptin and insulin in young adulthood are associated with weight in infancy
}

\author{
Umberto Simeoni ${ }^{1}$, Clive Osmond², Ricardo Garay³, Christophe Buffat ${ }^{4}$, Farid Boubred5, Christophe Chagnaud6, \\ Elisabeth Jouve7, Christine Audebert7 , Jean-Michel Antoine ${ }^{8}$ and Kent Thornburg9
}

\author{
1Division of Pediatrics \& DOHaD Laboratory, CHUV University Hospital and University of Lausanne, Lausanne, Switzerland \\ 2MRC Lifecourse Epidemiology Unit, University of Southampton, Southampton, UK \\ ${ }^{3}$ Craven, Villemoisson-sur-Orge, France \\ ${ }^{4}$ Laboratoire de Biochimie et de Biologie Moléculaire, Hôpital de la Conception, Marseille, France \\ ${ }^{5}$ Division of Neonatology, Assistance Publique, Hôpitaux de Marseille, Marseille, France \\ ${ }^{6}$ Division of Radiology and Medical Imaging, Assistance Publique, Hôpitaux de Marseille, Marseille, France \\ 7UPCET, Clinical Pharmacology, Assistance Publique, Hôpitaux de Marseille, Marseille, France \\ ${ }^{8}$ Danone Institute International, Paris, France \\ ${ }^{9} \mathrm{Bob}$ and Charlee Moore Institute for Nutrition and Wellness, Oregon Health \& Science University, Portland, Oregon, USA
}

Correspondence should be addressed to U Simeoni: Umberto.Simeoni@chuv.ch

\begin{abstract}
Low weight in early infancy is a known risk factor for cardio-metabolic syndrome in adult life. However, little is known either about developmental programming in subjects of normal birthweight or about events between the ages which separate early programming and the occurrence of disease at late adulthood. We tested the hypothesis that circulating concentrations of leptin, adiponectin and insulin in young, healthy adults, born with a birth size within the normal range, are influenced by early life growth patterns. In an observational study of 188 healthy volunteers aged 18-25 years (97 males, 91 females) we investigated the association of metabolic function with their birth size, their growth during childhood and their body composition. High plasma leptin in early adulthood, a risk factor for cardio-metabolic syndrome, was associated with low weight at age 2 years (correlation coefficient controlled for adult weight $=-0.21$, $P<0.01$ ). It was also positively associated with pre-prandial insulin and with HOMA (Homeostasis Model Assessment) insulin resistance. Leptin, leptin-adiponectin ratio and insulin correlated with lean mass, fat mass and percent fat $(P<0.0001)$. In conclusion, high leptin in early adulthood was associated with both low weight at age 2 years and insulin resistance. We speculate that high leptin is developmentally programmed and can contribute to the association between low weight in early infancy and increased cardio-metabolic risk in adulthood in healthy subjects.
\end{abstract}
Key Words
- birth weight
- coronary artery disease
- diabetes
- metabolic syndrome
- leptin
- adiponectin
- percentage fat

\section{Introduction}

Twenty-five years of evidence associate early nutrition and growth patterns during pregnancy, early infancy and the pre-conception period, with an elevated risk for chronic disease in later life, including cardiovascular disease and type 2 diabetes mellitus (T2DM). Barker and colleagues (Barker et al. 1989) first reported an inverse relationship between birthweight, weight at 1 year and risk of coronary heart disease among adults born in Hertfordshire, UK. They also found that low weight at the age of 1 year was associated with an increased risk for 
metabolic disease (Barker et al. 1993) and left ventricular hypertrophy in adulthood (Vijayakumar et al. 1995). The process by which early life stressors impart risk for adultonset disease is known as programming, but its biological underpinnings are not completely understood.

The risk of coronary events has been found to be related to low weight at birth and during infancy, followed by a rapid increase in BMI (BMI) after the age of 2 years (Barker et al. 2005). This pattern of childhood growth was associated with insulin resistance in later life.

The close link between T2DM and eventual cardiovascular disease (Manson et al. 1991, Grundy et al. 1999) led Hales and Barker to propose the 'thrifty phenotype' hypothesis (Hales \& Barker 2001), which provided a common origin for the two diseases. They suggested that sub-optimal fetal growth, associated with maternal malnutrition, programs an individual to be vulnerable for the metabolic syndrome (T2DM, high plasma triglycerides, low HDL cholesterol and hypertension) (Barker 2000)

Low birthweight babies have decreased muscle mass in infancy (Robinson et al. 1991), a condition maintained throughout life which makes them vulnerable for metabolic disease (Baker et al. 2010). Rapid growth of adolescents who were born small or prematurely is associated with endothelial dysfunction (Singhal et al. 2004, Ligi et al. 2011) and ischemic heart disease (Eriksson et al. 1999). Animal studies have characterized the role of nutrition during gestation and the early postnatal period in the later development of cardio-vascular and metabolic disorders at adulthood (Boubred et al. 2007, Yzydorczyk et al. 2017, Siddeek et al. 2018). Thus, one could reasonably expect that the regulation of metabolic hormones in adulthood is related to growth patterns during prenatal and early postnatal life. Variations of birth weight within the normal range have been shown to be sufficient to influence the cardio-metabolic risk (Barker et al. 1989). However little is known on developmental programming that occurs under the influence of variations in what is considered the normal environment, and on the time sequence across the period of the life course which separates early programming and the occurrence of disease at late adulthood.

Adipokines, such as leptin and adiponectin, and the pancreatic hormone insulin work in harmony to regulate appetite and a number of metabolic processes through their receptors. Leptin is best known as a powerful suppressor of appetite (Halaas et al. 1995) in people who have normal weight control but is elevated in people with a large fat mass (Friedman \& Mantzoros 2015).
When found in high concentrations leptin is associated with a number of adverse cardiovascular conditions including generalized inflammation (Otero et al. 2005) and endothelial dysfunction (Sweeney 2010). While circulating concentrations of leptin are generally proportional to body fat mass (Yang \& Barouch 2007), adiponectin concentrations are known to be depressed in people who have a BMI that exceeds $30 \mathrm{~kg} / \mathrm{m}^{2}$ (Lihn et al. 2005). Plasma concentrations of adiponectin are inversely related to systolic blood pressure (Huang et al. 2003) as well as to insulin resistance (Bacha et al. 2004). The ratio between circulating concentrations of leptin and adiponectin has been used as a marker for adverse outcomes in people at risk for diabetes and metabolic disease (Satoh et al. 2004). The ratio also correlates with the homeostasis model assessment of insulin resistance (HOMA-IR) during pregnancy (Skvarca et al. 2013). Therefore, all three hormones are related to metabolic health and when abnormal lead to cardiovascular disease.

Leptin is known to have an important role in developmental programming. Early life hyperleptinemia has been shown to affect the hardwiring of developing CNS, particularly hypothalamic appetite regulation areas, and the cardio-vascular sympathetic drive (Taylor et al. 2014). In contrast, neonatal leptin treatment has been shown to reverse altered developmental programming induced by fetal undernutrition in rodents (Vickers et al. 2005).

We sought to test the hypothesis that circulating concentrations of leptin, adiponectin and insulin in young, healthy adults, born with a birth size within the normal range, are influenced by early life growth patterns among normal young adults. To test the hypothesis, we sought to evaluate the relationship between birth size and growth patterns during childhood and the circulating concentrations of leptin, adiponectin and insulin young in 22-year-old university students. We studied 188 normal young men and women whose birth size, infant and childhood growth data had been recorded in their personal health records (the 'carnet de santé').

\section{Subjects and methods}

\section{Subjects}

We performed an observational study in 188 healthy volunteers, aged 18-25 years, recruited at the Centre de Médecine Préventive at Aix-Marseille Université, and at the Center for Clinical Investigation (UPCET) at Assistance-Publique Hôpitaux de Marseille, France. 
They had to be registered in the French Social Security system and to have growth data in their health records, including height and weight at birth, 4 months, 9 months, 2 years, 6 years and 12 years of age. The study was approved by the Comité de Protection des Personnes ${ }^{\circ} 2$ (Marseille, France) ethical review board. Subjects signed a consent form for the study. Subjects were excluded if they were born preterm, small for gestational age, had congenital heart disease, chronic endocrine or renal disease, metabolic disease acquired in childhood, non-idiopathic hypertension, non-idiopathic obesity, malignant disease or were pregnant. Subjects were typically students at the Faculty of Medicine, Aix-Marseille University.

\section{Assessments}

The following measurements were made at UPCET, over a 2-day time period.

\section{Anthropometry}

Height and weight at birth, 4 months, 9 months, 2 years, 6 years, 12 years of age were recorded from the subject's personal health care booklet. Height, weight, waist and hip circumferences were measured at the visit using a calibrated scale. BMI (weight/height ${ }^{2}$ ) and waist/hip ratio were derived.

\section{Body composition}

Total and regional (upper limbs, trunk, lower limbs) lean mass and fat mass were measured using dual-energy X-ray absorptiometry (DEXA) whole body scanning (DXA; Hologic, Bedford, MA, USA).

\section{Biochemical parameters}

Venous blood samples were collected after an overnight $(\geq 12 \mathrm{~h})$ fast and $2 \mathrm{~h}$ after a standardized breakfast. The samples were centrifuged at $+4^{\circ} \mathrm{C}$, aliquoted and immediately frozen for future analysis. Blood samples were also analyzed for concentrations of plasma glucose, triglycerides (TG), total cholesterol (TC), highdensity lipoprotein cholesterol (HDL-C), low-density lipoprotein cholesterol (LDL-C), insulin, adiponectin, leptin, homocysteine, ultrasensitive C-reactive protein and folic acid. Serum lipids (enzymatic methods) and plasma glucose (glucose oxidase method) were assayed using the UniCel DxC 600 automatic biochemistry analysis system (Beckman). HDL-C was measured directly.
LDL-C (mmol/L) was estimated using Friedewald's formula as TC (mmol/l)-HDL-C (mmol/l)-TG (mmol/l)/2.2\}. Adiponectin and leptin concentrations were measured by ELISA according to the manufacturer's instructions (R \& D System; SPI-Bio, France respectively) and insulin was determined by electrochemiluminescence (ECL) technology (Roche).

\section{Statistics}

\section{Descriptive statistics}

We used means and standard deviations as descriptive statistics for symmetrically distributed variables. We used medians and quartiles to describe variables that were skewed, and log transformation for their analysis (Tables 1 and 2).

Table 1 Descriptive data for anthropometric measurements.

\begin{tabular}{|c|c|c|c|c|}
\hline \multirow[b]{2}{*}{ Measurement } & \multicolumn{2}{|c|}{ Males $(n=97)$} & \multicolumn{2}{|c|}{ Females $(n=91)$} \\
\hline & Mean & S.D. & Mean & S.D. \\
\hline \multicolumn{5}{|l|}{ Birth } \\
\hline Height (cm) & 50.4 & 1.8 & 49.3 & 1.9 \\
\hline Weight (kg) & 3.38 & 0.42 & 3.21 & 0.47 \\
\hline BMI $\left(\mathrm{kg} / \mathrm{m}^{2}\right)$ & 13.3 & 1.2 & 13.2 & 1.4 \\
\hline \multicolumn{5}{|l|}{ Age 4 months } \\
\hline Height (cm) & 64.1 & 2.2 & 62.7 & 2.6 \\
\hline Weight (kg) & 6.95 & 0.74 & 6.40 & 0.73 \\
\hline $\mathrm{BMI}\left(\mathrm{kg} / \mathrm{m}^{2}\right)$ & 16.9 & 1.4 & 16.3 & 1.4 \\
\hline \multicolumn{5}{|l|}{ Age 9 months } \\
\hline Height (cm) & 72.6 & 2.4 & 70.8 & 2.5 \\
\hline Weight (kg) & 9.36 & 0.98 & 8.59 & 0.92 \\
\hline $\mathrm{BMI}\left(\mathrm{kg} / \mathrm{m}^{2}\right)$ & 17.8 & 1.5 & 17.1 & 1.3 \\
\hline \multicolumn{5}{|l|}{ Age 2 years } \\
\hline Height (cm) & 88.3 & 3.1 & 87.1 & 3.4 \\
\hline Weight (kg) & 12.9 & 1.4 & 12.0 & 1.4 \\
\hline BMI $\left(\mathrm{kg} / \mathrm{m}^{2}\right)$ & 16.5 & 1.3 & 15.8 & 1.3 \\
\hline \multicolumn{5}{|l|}{ Age 6 years } \\
\hline Height (cm) & 117.0 & 4.6 & 116.5 & 5.6 \\
\hline Weight (kg) & 21.4 & 2.7 & 20.9 & 3.0 \\
\hline $\mathrm{BMI}\left(\mathrm{kg} / \mathrm{m}^{2}\right)$ & 15.6 & 1.4 & 15.3 & 1.2 \\
\hline \multicolumn{5}{|l|}{ Age 12 years } \\
\hline Height (cm) & 150.1 & 8.0 & 151.1 & 9.4 \\
\hline Weight (kg) & 40.8 & 7.2 & 40.6 & 8.6 \\
\hline $\mathrm{BMI}\left(\mathrm{kg} / \mathrm{m}^{2}\right)$ & 18.0 & 2.3 & 17.6 & 2.3 \\
\hline \multicolumn{5}{|l|}{ Adult } \\
\hline Age (years) & 22.7 & 2.9 & 21.9 & 1.9 \\
\hline Height (cm) & 179.3 & 6.2 & 165.6 & 6.9 \\
\hline Weight (kg) & 72.3 & 8.8 & 57.5 & 8.9 \\
\hline BMI (kg/m²) & 22.5 & 2.3 & 20.9 & 2.4 \\
\hline Lean mass (kg) & 54.4 & 6.0 & 37.5 & 4.4 \\
\hline Fat mass (kg) & 15.3 & 5.3 & 18.4 & 5.3 \\
\hline Percentage fat & 21.7 & 5.8 & 32.5 & 5.1 \\
\hline Waist circumference $(\mathrm{cm})$ & 79.3 & 6.1 & 68.7 & 5.6 \\
\hline Hip circumference (cm) & 93.6 & 6.7 & 89.5 & 7.1 \\
\hline Waist/hip ratio (\%) & 84.7 & 4.5 & 76.8 & 5.3 \\
\hline Trunk fat (kg) & 7.2 & 2.9 & 7.7 & 2.5 \\
\hline
\end{tabular}


Table 2 Descriptive data for laboratory measurements.

\begin{tabular}{|c|c|c|c|c|c|}
\hline \multirow[b]{2}{*}{ Measurement } & \multicolumn{2}{|c|}{ Males $(n=97)$} & \multicolumn{2}{|c|}{ Females $(n=91)$} & \multirow[b]{2}{*}{$P$ diff } \\
\hline & Median & $\mathrm{LQ}, \mathrm{UQ}^{\mathrm{b}}$ & Median & $\mathrm{LQ}, \mathrm{UQ}$ & \\
\hline Leptin (ng/mL)a & 4.7 & $2.3,8.9$ & 18.6 & $13.4,32.0$ & $<0.001$ \\
\hline Adiponectin $(\mu \mathrm{g} / \mathrm{mL})$ & 5.4 & $4.4,7.4$ & 10.4 & $7.9,12.7$ & $<0.001$ \\
\hline Leptin/adiponectin ratioa & 0.9 & $0.3,1.7$ & 2.0 & $1.1,3.7$ & $<0.001$ \\
\hline Glucose - pre (mmol/L) & 4.8 & $4.5,5.0$ & 4.6 & $4.3,4.8$ & 0.002 \\
\hline Glucose - post (mmol/L) & 4.5 & $4.0,4.8$ & 4.5 & $4.2,4.9$ & 0.3 \\
\hline Insulin - pre (mui/L)a & 6.7 & $5.0,8.7$ & 7.6 & $5.8,10.1$ & 0.03 \\
\hline Insulin - post (mui/L)a & 10.4 & $5.9,15.7$ & 15.0 & $9.8,24.2$ & $<0.001$ \\
\hline HOMA insulin resistance ${ }^{a, c}$ & 1.4 & $1.0,1.9$ & 1.5 & $1.2,2.1$ & 0.1 \\
\hline C-peptide - pre (nmol/L)a & 0.56 & $0.47,0.67$ & 0.60 & $0.50,0.71$ & 0.04 \\
\hline C-peptide - post (nmol/L)a & 0.86 & $0.64,1.14$ & 1.22 & $0.89,1.52$ & $<0.001$ \\
\hline Total cholesterol - pre (mmol/L) & 4.1 & $3.6,4.8$ & 4.6 & $4.0,5.2$ & $<0.001$ \\
\hline Total cholesterol - post (mmol/L) & 4.0 & $3.5,4.9$ & 4.6 & $4.1,5.0$ & $<0.001$ \\
\hline HDL cholesterol - pre (mmol/L) & 1.2 & $1.0,1.4$ & 1.5 & $1.3,1.9$ & $<0.001$ \\
\hline HDL cholesterol - post (mmol/L) & 1.2 & $1.0,1.4$ & 1.6 & $1.3,1.9$ & $<0.001$ \\
\hline LDL cholesterol - pre (mmol/L) & 2.4 & $2.0,3.1$ & 2.5 & $2.0,3.0$ & 0.7 \\
\hline LDL cholesterol - post (mmol/L) & 2.4 & $2.0,3.0$ & 2.4 & $2.0,3.0$ & 0.6 \\
\hline Triglycerides - pre $(\mathrm{mmol} / \mathrm{L})^{a}$ & 0.73 & $0.54,0.93$ & 0.82 & $0.60,1.08$ & 0.09 \\
\hline Triglycerides - post $(\mathrm{mmol} / \mathrm{L})^{a}$ & 0.75 & $0.62,0.96$ & 0.83 & $0.61,1.13$ & 0.2 \\
\hline C-reactive protein $(\mathrm{mg} / \mathrm{L})^{a}$ & 0.6 & $0.4,1.5$ & 1.6 & $0.8,4.6$ & $<0.001$ \\
\hline Homocysteine (mcmo/L)a & 11.7 & $9.7,15.1$ & 9.5 & $8.1,11.3$ & $<0.001$ \\
\hline Folic acid (nmol/L) & 13.8 & $11.7,17.9$ & 16.4 & $13.3,19.7$ & 0.002 \\
\hline
\end{tabular}

$P$ diff is the $P$ value for the difference between males and females.

aVariables with right-skewed distributions, which are analysed after log transformation. bLQ and UQ are the lower and upper quartiles respectively.

'Calculated as glucose-pre $\mathrm{x}$ insulin-pre/22.5.

Table 3 Partial correlation coefficients between measures of adult body composition and concentrations of leptin, adiponectin, their ratio and insulin.

\begin{tabular}{l}
\hline Body composition \\
\hline Measure \\
\hline Correlations controlled for sex and adult age \\
Height \\
Weight \\
BMI \\
Lean mass \\
Fat mass \\
Percent fat \\
Waist circumference \\
Hip circumference \\
Waist/hip ratio \\
Trunk fat \\
Correlations controlled for sex, adult age and weight \\
Height \\
BMI \\
Lean mass \\
Fat mass \\
Percent fat \\
Waist circumference \\
Hip circumference \\
Waist/hip ratio \\
Trunk fat
\end{tabular}

\begin{tabular}{cccc}
\hline & & \\
\cline { 1 - 1 } Leptin & & Adiponectin \\
-0.06 & & 0.08 \\
$0.40^{a}$ & & -0.07 \\
$0.53^{a}$ & & -0.14 \\
-0.05 & & -0.08 \\
$0.68^{a}$ & & -0.02 \\
$0.75^{a}$ & & -0.02 \\
$0.49^{a}$ & & -0.16 \\
$0.41^{a}$ & & -0.09 \\
0.11 & & -0.10 \\
$0.68^{a}$ & & -0.06 \\
& & \\
$-0.40^{a}$ & & 0.15 \\
$0.39^{a}$ & & -0.14 \\
$-0.64^{a}$ & & -0.04 \\
$0.66^{a}$ & & 0.06 \\
$0.69^{a}$ & & 0.02 \\
$0.31^{a}$ & & -0.17 \\
0.18 & & -0.06 \\
0.10 & & -0.09 \\
$0.63^{a}$ & & -0.00 \\
\hline
\end{tabular}

\begin{tabular}{|c|c|}
\hline Leptin/adiponectin & Insulin \\
\hline-0.08 & -0.00 \\
\hline $0.39^{a}$ & 0.21 \\
\hline $0.53^{a}$ & $0.26^{a}$ \\
\hline 0.02 & -0.03 \\
\hline $0.59 a$ & $0.33^{a}$ \\
\hline $0.64^{a}$ & $0.37^{a}$ \\
\hline $0.52^{a}$ & $0.27^{a}$ \\
\hline $0.40^{a}$ & 0.20 \\
\hline 0.16 & 0.09 \\
\hline $0.61^{a}$ & $0.33^{a}$ \\
\hline$-0.41^{a}$ & -0.16 \\
\hline $0.40^{a}$ & 0.16 \\
\hline$-0.51^{a}$ & $-0.32^{a}$ \\
\hline $0.51^{a}$ & $0.29 a$ \\
\hline $0.56^{a}$ & $0.31^{a}$ \\
\hline $0.37 a$ & 0.18 \\
\hline 0.17 & 0.07 \\
\hline 0.16 & 0.08 \\
\hline $0.52^{a}$ & 0.28 \\
\hline
\end{tabular}

The table includes 76 comparisons. Using Bonferroni correction the critical $P$ value is 0.0006 . a $P<0.0006$.

\begin{tabular}{|c|c|}
\hline $\begin{array}{l}\text { https://joe.bioscientifica.com } \\
\text { https://doi.org/10.1530/lOE-18-0538 }\end{array}$ & (c) 2020 Society for Endocrinology \\
\hline
\end{tabular}
Printed in Great Britain 
Table 4 Partial correlation coefficients between weight at different ages and adult concentrations of leptin, adiponectin, their ratio and insulin.

\begin{tabular}{l}
\hline Age \\
\hline Correlations controlled for sex and adult age \\
Birth \\
4 months \\
9 months \\
2 years \\
6 years \\
12 years \\
Adult life \\
Correlations controlled for sex, adult age and weight \\
Birth \\
4 months \\
9 months \\
2 years \\
6 years \\
12 years
\end{tabular}

\begin{tabular}{c}
\hline Leptin \\
\hline 0.03 \\
0.08 \\
0.01 \\
-0.08 \\
0.11 \\
0.13 \\
$0.40^{a}$ \\
-0.06 \\
-0.09 \\
-0.19 \\
-0.39 \\
-0.25 \\
-0.14 \\
\hline
\end{tabular}

\begin{tabular}{c}
\hline Adiponectin \\
\hline \\
0.08 \\
0.15 \\
0.08 \\
0.10 \\
0.11 \\
0.11 \\
-0.07 \\
\\
0.10 \\
0.19 \\
0.12 \\
0.16 \\
0.22 \\
0.18 \\
\hline
\end{tabular}

\begin{tabular}{c}
\hline Leptin/adiponectin \\
\hline-0.05 \\
0.03 \\
-0.00 \\
-0.11 \\
0.06 \\
0.08 \\
$0.39 a$ \\
\\
-0.14 \\
-0.15 \\
-0.20 \\
$-0.41^{a}$ \\
$-0.31^{a}$ \\
-0.19
\end{tabular}

\begin{tabular}{r}
\hline Insulin \\
\hline \\
0.01 \\
0.07 \\
0.01 \\
-0.06 \\
0.03 \\
0.04 \\
0.21 \\
\\
-0.03 \\
-0.01 \\
-0.08 \\
-0.21 \\
-0.16 \\
-0.10
\end{tabular}

The table includes 52 comparisons. Using Bonferroni correction the critical $P$ value is 0.001 .

$\star P<0.001$.

\section{Measurement of association}

We measured the strength of association among metabolic measures and with weight at each age using partial correlation coefficients, for which control was made for sex and for adult age and sometimes weight (Tables 3, 4 and 7). We also used tabulation of mean values according to groups of growth and adult size to illustrate these results (Table 6).

\section{Growth}

We expressed growth in weight in the interval from birth to age 2 years using the conditional approach. In this the residual from the sex-specific regression of weight at age 2 years on birth weight is expressed as a standardized score. This measure expresses growth in infancy beyond that predicted from birth size, with which it is statistically uncorrelated. We then analysed outcomes using a regression model which included sex, adult age, birth weight, infant growth and adult weight as the predictors (Table 5). As an alternative approach we used principal component analysis to identify the three most varying characteristic of the full set of growth measures and used these components in regression models (Supplementary materials, see section on supplementary materials given at the end of this article).

\section{Multiple testing}

To control the number of possible false-positive associations we used Bonferroni correction of $P$ values in each analysis. The $P$ values required to declare statistical significance are given in the footnote to each table.

(C) 2020 Society for Endocrinology Published by Bioscientifica Ltd. Printed in Great Britain

\section{Results}

We studied 188 subjects (97 males, 91 females) aged around 22 years. Their body size at birth, 4, 9 months, 2, 6, 12 years and in adult life is described in Table 1 and illustrated in Fig. 1 using WHO standards for comparison. As expected, differences in size between sexes arose after puberty, with higher lean mass and lower percent fat in males. Birth weight was below $2.5 \mathrm{~kg}$ for $2 \%$ of males and $7 \%$ of females, and above $4 \mathrm{~kg}$ for $3 \%$ and $7 \%$, respectively. BMI $\left(\mathrm{kg} / \mathrm{m}^{2}\right)$ in adulthood was below 20 in 11 and 42\%; between 20 and 25 in 73 and $55 \%$ and above 25 in 15 and 3\% respectively. None had a BMI above 30 .

Descriptive data for pre- and post-prandial plasma measurements are shown in Table 2. Mean plasma concentrations of leptin, adiponectin, insulin and C-peptide were higher in females than in males.

Adult leptin and adiponectin concentrations, their ratio and insulin concentration were associated with adult measures of body composition. The top half of Table 3 shows that, controlling for age and sex, leptin and its ratio were positively associated with current weight, BMI, fat mass, percent fat, waist and hip circumferences and trunk fat mass. The strongest associations were with percent fat. Adiponectin concentration was not significantly associated with adult body composition measures, but insulin was associated with fat mass, percent fat and fat mass. When further controlling for current weight, leptin and its ratio were also negatively associated with height and lean mass. Again, adiponectin was not significantly associated with any measure of body composition. 


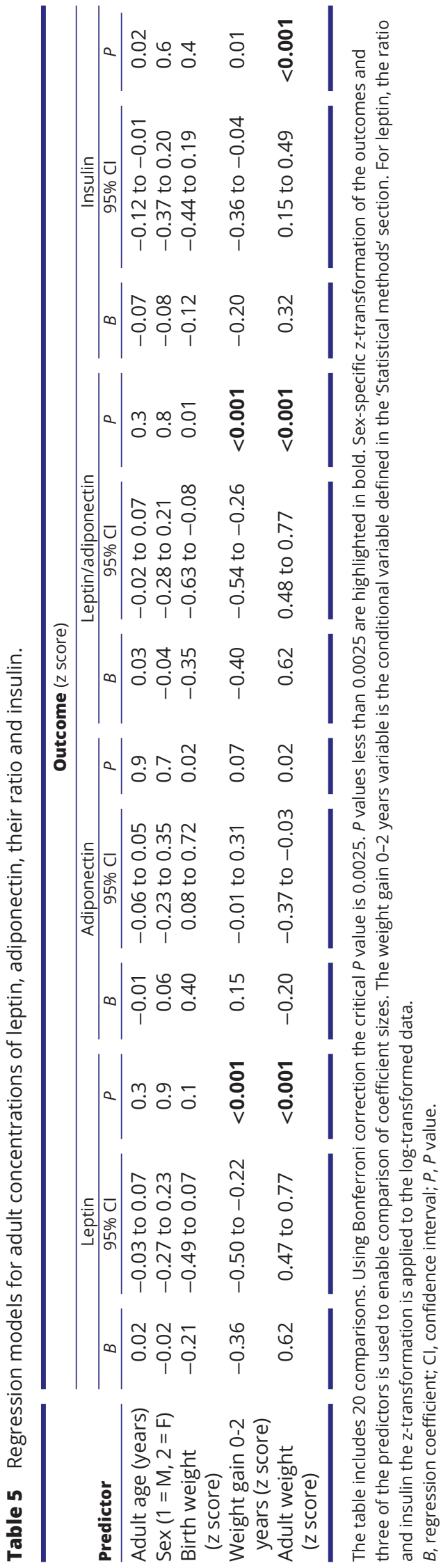

https://joe.bioscientifica.com

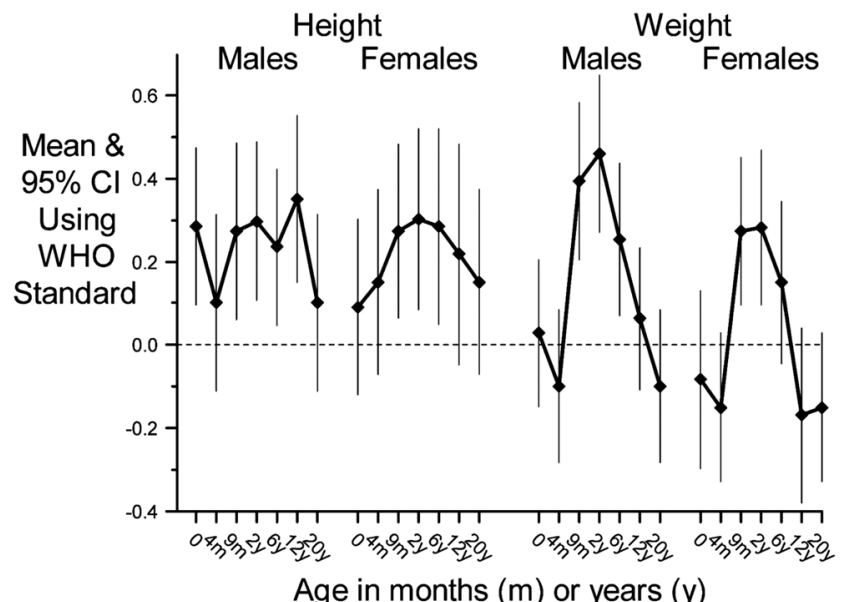

Figure 1

Means and $95 \%$ confidence intervals of the heights and weights of the males and females in the study at each stage of measurement, expressed using WHO standards (https://www.who.int/childgrowth/en/).

As shown in Fig. 2 the relationship between circulating leptin concentrations and fat mass was different for men and women. Women had higher concentrations for each $\mathrm{kg}$ of fat mass than men. Log leptin increased by 0.131 (95\% CI 0.106-0.157) per kg of fat mass in men, but only by $0.087(0.064-0.109)$ in women $(P$ for difference $=0.008)$. However, when fat mass was expressed as a percentage of body weight, leptin concentrations were linearly associated with percent fat in both sexes, with women's concentrations and percentages of fat generally at the higher end of the curve (Fig. 2). Log leptin concentration increased by $0.126(0.104-0.149)$ per unit of percentage fat in men and by $0.103(0.082-0.124)$ in women ( $P$ for difference $=0.12$ ).

Table 4 shows the associations of weights at birth and at ages through to adulthood with adult leptin and adiponectin concentrations, their ratio and insulin concentration. In the top half of the table, adjustments were made for the subject's adult age and sex. Leptin concentrations and its ratio to adiponectin were only associated with adult weight. Further adjusting for current adult weight, as in the bottom half of the table, leptin and its ratio were negatively associated with the subjects' weight at age 2 years and, more weakly at age 6 years.

Table 5 shows regression models for leptin, adiponectin, their ratio and insulin in which the individual's growth trajectory is expressed by birth size, conditional infant growth and adult size. Leptin and the ratio were significantly negatively associated with both adult weight and with infant growth. The pattern for insulin was similar but a little weaker. That with adiponectin was weaker still and in the reverse direction. 
A
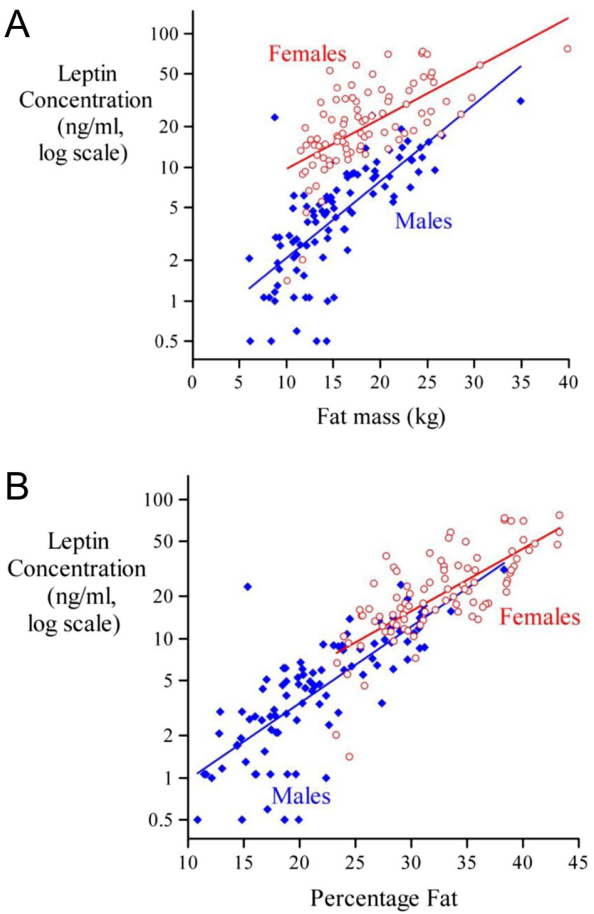

Figure 2

Associations between plasma leptin concentration and (A) fat mass and (B) fat percentage, shown separately for men and women.

Results from an alternative approach based on principal component analysis of all the weights are given in the Supplementary materials. These analyses highlight the specificity of the early changes in weight in the prediction of leptin, adiponectin, their ratio and insulin concentration. Measures that are based on average weights or linear trends in weight, for example, are much less predictive.

Table 6 illustrates how values of the leptin/adiponectin ratio vary according to sex-specific thirds of weight at age 2 years and adult weight. For males and for females the ratio tends to increase along the rows of the table as adult weight increases, but decreases down the columns as weight at age 2 years increases. A further illustration is given in Fig. 3, which shows how leptin, adiponectin and their ratio, when controlled by regression for sex, adult age and weight at their mean values, are associated with weight at age 2 years, which is divided into fifths.

In Table 7 we explore the associations of leptin and adiponectin concentrations with measures related to glucose regulation: insulin, HOMA-IR, C-peptide and with lipid concentrations. Adjusting for adult age and sex in the top half of the table, leptin and the ratio are positively associated with pre-prandial insulin and C-peptide and with HOMA insulin resistance. Adiponectin is positively associated with HDL cholesterol concentration. Further adjustment for percent fat in the bottom half of the table tends to attenuate these associations, but not to change the overall pattern.

\section{Discussion}

Previous studies have been designed to determine the degree to which low body weight in infancy is associated with elevated risk of metabolic disease, including insulin resistance and type 2 diabetes, in adult life. In contrast, this study was designed to determine whether the regulation of metabolic hormones in healthy 22-year-old subjects was associated with growth patterns throughout childhood, with the aim of better understanding the natural history of developmentally programmed regulations. We investigated three important regulators of metabolism; adipose-derived leptin and adiponectin and pancreatic insulin. The primary finding of the study is that plasma concentrations of leptin as well as of insulin in young, healthy adults may be developmentally programmed.

Table 6 Mean leptin to adiponectin ratioa according to weight at age 2 years and weight in adult life in males and in females.

\begin{tabular}{l} 
Thirds of weight at age 2 years \\
\hline Males \\
Low ( $\leq 12.4 \mathrm{~kg})$ \\
Intermediate $(-13.3 \mathrm{~kg})$ \\
High (>13.3 kg) \\
All \\
Females \\
Low ( $\leq 11.5 \mathrm{~kg})$ \\
Intermediate $(-12.4 \mathrm{~kg})$ \\
High (>12.4 kg) \\
All
\end{tabular}

\begin{tabular}{c}
\hline Low \\
\hline$(\leq 67.5 \mathrm{~kg})$ \\
$0.74_{22}$ \\
$0.33_{4}$ \\
$0.18_{5}$ \\
$0.53_{31}$ \\
$(\leq 53.0 \mathrm{~kg})$ \\
$1.45_{16}$ \\
$1.63_{8}$ \\
$1.24_{7}$ \\
$1.44_{31}$ \\
\hline
\end{tabular}

\begin{tabular}{c} 
Thirds of weight in adult life \\
\hline Intermediate \\
\hline$(-77.0 \mathrm{~kg})$ \\
$0.98_{8}$ \\
$0.66_{16}$ \\
$0.46_{11}$ \\
$0.64_{35}$ \\
$(-59.5 \mathrm{~kg})$ \\
$3.45_{11}$ \\
$1.60_{12}$ \\
$0.66_{6}$ \\
$1.78_{29}$
\end{tabular}

\begin{tabular}{c} 
High \\
\hline$(>77.0 \mathrm{~kg})$ \\
$1.75_{3}$ \\
$2.07_{11}$ \\
$1.00_{17}$ \\
$1.37_{31}$ \\
$(>59.5 \mathrm{~kg})$ \\
$4.78_{3}$ \\
$2.82_{10}$ \\
$3.05_{18}$ \\
$3.11_{31}$
\end{tabular}

All

$0.85_{33}$

$0.90_{31}$

$0.60_{33}$

$0.77_{97}$

$2.25_{30}$

$1.94_{30}$

$1.85_{31}$

$2.01_{91}$

Suffices are numbers of subjects.

avalues are geometric and adjusted for adult age. 
A

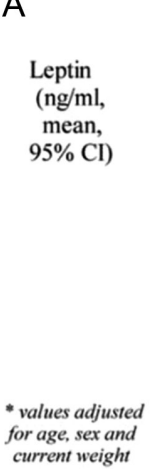

B

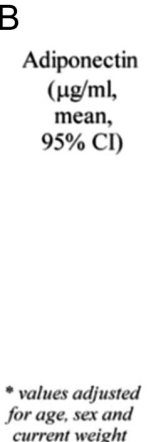

C

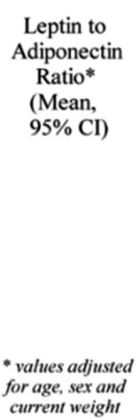

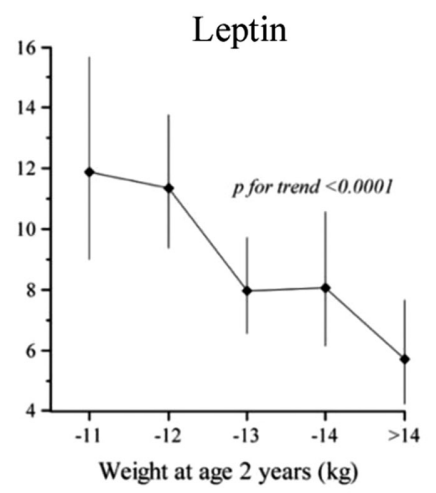

Adiponectin

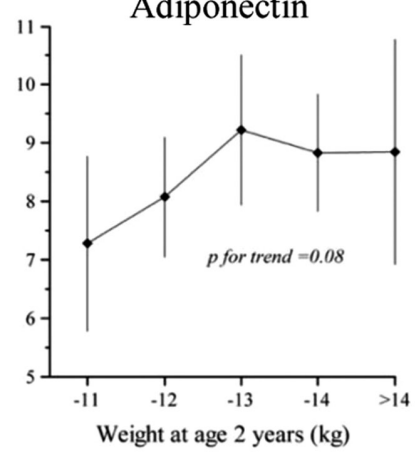

Leptin to Adiponectin Ratio

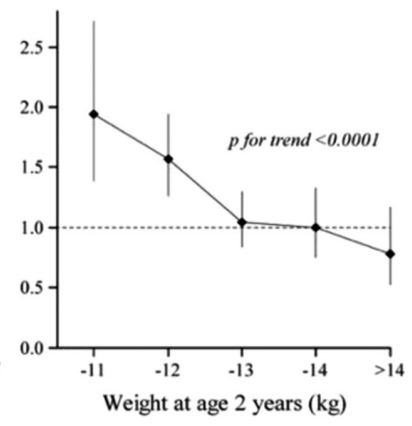

Figure 3

Mean values (95\% confidence intervals) of leptin (A), adiponectin (B) and their ratio (C) at young adult age according to weight at age 2 years, divided into fifths. Values are adjusted for sex and adult age and weight by regression to the mean values of these variables.

We found that leptin and insulin at adulthood in young adult life are negatively correlated with weight at 2 years of age when adjusted for age, sex and current weight (Tables 4, 5 and 6 and Fig. 3). Thus, 22-year-old men and women had higher concentrations of leptin and insulin if they had low body weight as 2 year olds. This finding may have high physiologic significance, because the effect size is similar to that of increasing body weight at young adulthood (Table 6). This suggests that

the regulatory 'set points' for both circulating leptin and insulin concentrations are determined in early childhood.

We speculate that these findings have important implications:

1) Several aspects of metabolic control in young adults are associated with the nutritional environments of those individuals between birth and late infancy.

2) The propensity for the subjects in this study to acquire chronic diseases in later life may also relate to their growth patterns in childhood. If true, this finding represents another physiological link between early life growth and later life disease. Proof of this speculation will require studies of these subjects in future years.

As expected, each of the anatomic constituents related to body fat mass is correlated with leptin concentrations (Table 3). Previous studies have shown that high leptin concentrations are a risk factor for cardiovascular disease, irrespective of obesity (Koh et al. 2008). In the West of Scotland Coronary Prevention Study leptin was an independent risk factor for coronary heart disease (Wallace et al. 2001). Moreover, high leptin concentrations have been found in patients with first-ever myocardial infarction (Söderberg et al. 1999), in acute ST segment elevation myocardial infarction (Jose et al. 2005, Taneli et al. 2006) and in hypertensive patients with myocardial infarction (Wallerstedt et al. 2004). We speculate that the concentrations of leptin that exceed those expected by their fat mass are associated with later cardiovascular and metabolic disease risk.

We found that women have leptin concentrations that exceed those of men, even out of proportion to their larger fat mass, suggesting that adipose tissue releases more leptin per gram in women than in men. This is not a new finding. However, it is interesting to note that leptin concentrations are more closely associated with percent body fat in young healthy adults than to fat mass itself. This fact, together with the inverse relationship between leptin concentrations and 2-year-old weight, suggests that the regulation of leptin in the circulation blood of healthy, 22-year olds may be acting through the programming of body composition in early childhood. This may occur as a consequence of the low infant fat intakes which characterize the nutrition in early infancy of certain subjects who tend to develop overweight or obesity as young adults, as shown in a prospective cohort study in France (Rolland-Cachera et al. 2013).

Moreover, we found high leptin associated with high C-peptide concentration, which may be involved in the mechanism of central lipid resistance (Koh et al. 2008). 
Table 7 Partial correlation coefficients between adult metabolic measures and concentrations of leptin, adiponectin and their ratio in adult life.

\begin{tabular}{l}
\hline Metabolic measure \\
\hline Correlations controlled for sex and adult age \\
Glucose - pre \\
Glucose - post \\
Insulin - pre \\
Insulin - post \\
HOMA insulin resistance \\
C-peptide - pre \\
C-peptide - post \\
Total cholesterol - pre \\
Total cholesterol - post \\
HDL cholesterol - pre \\
HDL cholesterol - post \\
LDL cholesterol - pre \\
LDL cholesterol - post \\
Triglycerides - pre \\
Triglycerides - post \\
C-reactive protein \\
Homocysteine \\
Folic acid \\
Correlations controlled for sex, adult age and weight \\
Glucose - pre \\
Glucose - post \\
Insulin - pre \\
Insulin - post \\
HOMA insulin resistance \\
C-peptide - pre \\
C-peptide - post \\
Total cholesterol - pre \\
Total cholesterol - post \\
HDL cholesterol - pre \\
HDL cholesterol - post \\
LDL cholesterol - pre \\
LDL cholesterol - post \\
Triglycerides - pre \\
Triglycerides - post \\
C-reactive protein \\
Homocysteine \\
Folic acid \\
\hline
\end{tabular}

\begin{tabular}{c}
\hline Leptin \\
\hline \\
0.24 \\
0.05 \\
$0.53^{a}$ \\
0.11 \\
$0.52^{a}$ \\
$0.42^{a}$ \\
-0.00 \\
0.23 \\
0.26 \\
-0.01 \\
0.06 \\
0.24 \\
0.25 \\
0.20 \\
0.22 \\
0.15 \\
-0.16 \\
-0.02
\end{tabular}

Adiponectin

Leptin/adiponectin

$-0.14$

$0.41^{\mathrm{a}}$

0.07

$0.38^{a}$

$0.40^{\mathrm{a}}$

0.05

0.13

0.12

0.13

0.13

0.06

0.04

0.10

0.09

0.02

$-0.07$

$-0.11$
$-0.08$

$-0.15$

$-0.11$

$-0.10$

$-0.11$

$-0.07$

$-0.10$

0.09

0.07

$0.27^{a}$

$0.31^{a}$

$-0.07$

$-0.09$

0.04

$-0.06$

0.01

$-0.08$

0.04

$-0.08$

$-0.15$

$-0.11$

$-0.10$

$-0.12$

$-0.06$

$-0.10$

0.09

0.08

$0.27 \mathrm{a}$

$0.30^{\mathrm{a}}$

$-0.07$

$-0.09$

0.05

$-0.06$

0.01

$-0.08$

0.04
0.25

0.12

$0.48^{a}$

0.09

$0.48^{\mathrm{a}}$

$0.35^{a}$

0.01

0.14

0.19

$-0.14$

$-0.09$

0.22

0.24

0.16

0.23

0.11

$-0.10$

$-0.02$

0.13

$-0.01$

$0.34^{a}$

0.06

$0.33^{a}$

0.29 a

0.05

0.03

0.04

$-0.08$

$-0.09$

0.06

0.06

0.06

0.12

$-0.00$

$-0.00$

$-0.09$

The table includes 108 comparisons. Using Bonferroni correction the critical $P$ value is 0.0005 . a $P<0.0005$.

Adiponectin concentrations were unrelated to fat mass in either males or females, as seen by others (Baratta et al. 2004). However, concentrations in young adults were positively correlated with weight at 4 months and 6 years. A low concentration of adiponectin is an independent risk factor for developing the metabolic syndrome (Renaldi et al. 2009) and T2DM (Hara et al. 2005, Vasseur et al. 2006). Therefore, our finding of low adiponectin associated with low weight at age 2 years deserves further investigation.

Several limitations of this study should be taken into consideration. The study is observational and does not allow a causal inference. Potential known or unknown confounding factors, such as educational level, dietary factors and physical activity may have altered the study findings. Alternative causal patterns, not involving confounders, can explain our observations.

In conclusion, this study suggests that plasma leptin concentration is programmed during early life as revealed in normal young men and women, when the rates of chronic disease are low. This may further explain the correlation between low weight in early infancy and increased risk of coronary heart disease in adulthood (Barker et al. 1989, Zohdi et al. 2014). High leptin can be one important etiological factor for the early origin of cardio-metabolic syndrome in adult life (Zohdi et al. 2014). 


\section{Supplementary materials}

This is linked to the online version of the paper at https://doi.org/10.1530/ JOE-18-0538.

\section{Declaration of interest}

The authors declare that there is no conflict of interest that could be perceived as prejudicing the impartiality of the research reported.

\section{Funding}

This study was supported by an unrestricted grant from Danone Institute International, Paris, France.

\section{Author contribution statement}

All authors have contributed equally to this work.

\section{Acknowledgments}

This article is dedicated to the memory of Prof. David J P Barker, the founder of the field of developmental origins of health and disease and a dear colleague to all of us.

\section{References}

Bacha F, Saad R, Gungor N \& Arslanian SA 2004 Adiponectin in youth: relationship to visceral adiposity, insulin sensitivity, and beta-cell function. Diabetes Care 27 547-552. (https://doi.org/10.2337/ diacare.27.2.547)

Baker J, Workman M, Bedrick E, Frey MA, Hurtado M \& Pearson O 2010 Brains versus brawn: an empirical test of Barker's brain sparing model. American Journal of Human Biology 22 206-215. (https://doi. org/10.1002/ajhb.20979)

Baratta R, Amato S, Degano C, Farina MG, Patanè G, Vigneri R \& Frittitta L 2004 Adiponectin relationship with lipid metabolism is independent of body fat mass: evidence from both cross-sectional and intervention studies. Journal of Clinical Endocrinology and Metabolism 89 2665-2671. (https://doi.org/10.1210/jc.2003-031777)

Barker DJ 2000 In utero programming of cardiovascular disease. Theriogenology 53 555-574. (https://doi.org/10.1016/s0093691x(99)00258-7)

Barker DJP, Osmond C, Winter PD, Margetts B \& Simmonds SJ 1989 Weight in infancy and death from ischaemic heart disease. Lancet 334 577-580.

Barker DJ, Hales CN, Fall CH, Osmond C, Phipps K \& Clark PM 1993 Type 2 (non-insulin-dependent) diabetes mellitus, hypertension and hyperlipidaemia (syndrome $\mathrm{X}$ ): relation to reduced fetal growth. Diabetologia 36 62-67. (https://doi.org/10.1007/bf00399095)

Barker DJ, Osmond C, Forsén TJ, Kajantie E \& Eriksson JG 2005 Trajectories of growth among children who have coronary events as adults. New England Journal of Medicine 353 1802-1809. (https://doi. org/10.1056/NEJMoa044160)

Boubred F, Buffat C, Feuerstein JM, Daniel L, Tsimaratos M, Oliver C, Lelièvre-Pégorier M \& Simeoni U 2007 Effects of early postnatal hypernutrition on nephron number and long-term renal function and structure in rats. American Journal of Physiology: Renal Physiology 293 F1944-F1949. (https://doi.org/10.1152/ajprenal.00141.2007)
Eriksson JG, Forsén T, Tuomilehto J, Winter PD, Osmond C \& Barker DJ 1999 Catch-up growth in childhood and death from coronary heart disease: longitudinal study. BMJ 318 427-431. (https://doi. org/10.1136/bmj.318.7181.427)

Friedman JM \& Mantzoros CS 201520 years of leptin: from the discovery of the leptin gene to leptin in our therapeutic armamentarium. Metabolism: Clinical and Experimental 64 1-4. (https://doi. org/10.1016/j.metabol.2014.10.023)

Grundy SM, Benjamin IJ, Burke GL, Chait A, Eckel RH, Howard BV, Mitch W, Smith SC \& Sowers JR 1999 Diabetes and cardiovascular disease: a statement for healthcare professionals from the American Heart Association. Circulation 100 1134-1146. (https://doi. org/10.1161/01.cir.100.10.1134)

Halaas JL, Gajiwala KS, Maffei M, Cohen SL, Chait BT, Rabinowitz D, Lallone RL, Burley SK \& Friedman JM 1995 Weight-reducing effects of the plasma protein encoded by the obese gene. Science 269 543-546. (https://doi.org/10.1126/science.7624777)

Hales CN \& Barker DJ 2001 The thrifty phenotype hypothesis. British Medical Bulletin 60 5-20. (https://doi.org/10.1093/bmb/60.1.5)

Hara K, Yamauchi T \& Kadowaki T 2005 Adiponectin: an adipokine linking adipocytes and type 2 diabetes in humans. Current Diabetes Reports 5 136-140. (https://doi.org/10.1007/s11892-005-0041-0)

Huang KC, Chen CL, Chuang LM, Ho SR, Tai TY \& Yang WS 2003 Plasma adiponectin levels and blood pressures in nondiabetic adolescent females. Journal of Clinical Endocrinology and Metabolism 88 41304134. (https://doi.org/10.1210/jc.2003-030158)

Jose VJ, Mariappan P, George PV \& Selvakumar D 2005 Serum leptin levels in acute myocardial infarction. Indian Heart Journal 57 39-43.

Koh KK, Park SM \& Quon MJ 2008 Leptin and cardiovascular disease: response to therapeutic interventions. Circulation 117 3238-3249. (https://doi.org/10.1161/CIRCULATIONAHA.107.741645)

Ligi I, Simoncini S, Tellier E, Vassallo PF, Sabatier F, Guillet B, Lamy E, Sarlon G, Quemener C, Bikfalvi A, et al. 2011 A switch toward angiostatic gene expression impairs the angiogenic properties of endothelial progenitor cells in low birth weight preterm infants. Blood 118 1699-1709. (https://doi.org/10.1182/blood-2010-12-325142)

Lihn AS, Pedersen SB \& Richelsen B 2005 Adiponectin: action, regulation and association to insulin sensitivity. Obesity Reviews 6 13-21. (https://doi.org/10.1111/j.1467-789X.2005.00159.x)

Manson JE, Colditz GA, Stampfer MJ, Willett WC, Krolewski AS, Rosner B, Arky RA, Speizer FE \& Hennekens CH 1991 A prospective study of maturity-onset diabetes mellitus and risk of coronary heart disease and stroke in women. Archives of Internal Medicine 151 1141-1147.

Otero M, Lago R, Lago F, Casanueva FF, Dieguez C, Gómez-Reino JJ \& Gualillo O 2005 Leptin, from fat to inflammation: old questions and new insights. FEBS Letters 579 295-301. (https://doi.org/10.1016/j. febslet.2004.11.024)

Renaldi O, Pramono B, Sinorita H, Purnomo LB, Asdie RH \& Asdie AH 2009 Hypoadiponectinemia: a risk factor for metabolic syndrome. Acta Medica Indonesiana 41 20-24.

Robinson SM, Wheeler T, Hayes MC, Barker DJ \& Osmond C 1991 Fetal heart rate and intrauterine growth. British Journal of Obstetrics and Gynaecology 98 1223-1227.

Rolland-Cachera MF, Maillot M, Deheeger M, Souberbielle JC, Péneau S \& Hercberg S 2013 Association of nutrition in early life with body fat and serum leptin at adult age. International Journal of Obesity $\mathbf{3 7}$ 1116-1122. (https://doi.org/10.1038/ijo.2012.185)

Satoh N, Naruse M, Usui T, Tagami T, Suganami T, Yamada K, Kuzuya H, Shimatsu A \& Ogawa Y 2004 Leptin-to-adiponectin ratio as a potential atherogenic index in obese type 2 diabetic patients. Diabetes Care 27 2488-2490. (https://doi.org/10.2337/diacare.27.10.2488)

Siddeek B, Li N, Mauduit C, Chehade H, Rigal E, Tolsa JF, Armengaud JB, Yzydorczyk C, Benahmed M, Vergely C, et al. 2018 Transient postnatal over nutrition induces long-term alterations in cardiac NLRP3inflammasome pathway. Nutrition, Metabolism, and Cardiovascular Diseases 28 944-951. (https://doi.org/10.1016/j.numecd.2018.03.013) 
Singhal A, Cole TJ, Fewtrell M, Deanfield J \& Lucas A 2004 Is slower early growth beneficial for long-term cardiovascular health? Circulation 109 1108-1113. (https://doi.org/10.1161/01.CIR.0000118500.23649.DF)

Skvarca A, Tomazic M, Blagus R, Krhin B \& Janez A 2013 Adiponectin/ leptin ratio and insulin resistance in pregnancy. Journal of International Medical Research 41 123-128. (https://doi. org/10.1177/0300060513476409)

Söderberg S, Ahrén B, Jansson JH, Johnson O, Hallmans G, Asplund K \& Olsson T 1999 Leptin is associated with increased risk of myocardial infarction. Journal of Internal Medicine 246 409-418. (https://doi. org/10.1046/j.1365-2796.1999.00571.x)

Sweeney G 2010 Cardiovascular effects of leptin. Nature Reviews: Cardiology 7 22-29. (https://doi.org/10.1038/nrcardio.2009.224)

Taneli F, Yegane S, Ulman C, Tikiz H, Bilge AR, Ari Z \& Uyanik BS 2006 Increased serum leptin concentrations in patients with chronic stable angina pectoris and ST-elevated myocardial infarction. Angiology $\mathbf{5 7}$ 267-272. (https://doi.org/10.1177/000331970605700302)

Taylor PD, Samuelsson AM \& Poston L 2014 Maternal obesity and the developmental programming of hypertension: a role for leptin. Acta Physiologica 210 508-523. (https://doi.org/10.1111/apha.12223)

Vasseur F, Meyre D \& Froguel P 2006 Adiponectin, type 2 diabetes and the metabolic syndrome: lessons from human genetic studies. Expert Reviews in Molecular Medicine 8 1-12. (https://doi.org/10.1017/ S1462399406000147)

Vickers MH, Gluckman PD, Coveny AH, Hofman PL, Cutfield WS, Gertler A, Breier BH \& Harris M 2005 Neonatal leptin treatment reverses developmental programming. Endocrinology 146 4211-4216. (https://doi.org/10.1210/en.2005-0581)

Vijayakumar M, Fall CH, Osmond C \& Barker DJ 1995 Birth weight, weight at one year, and left ventricular mass in adult life. British Heart Journal 73 363-367. (https://doi.org/10.1136/hrt.73.4.363)

Wallace AM, McMahon AD, Packard CJ, Kelly A, Shepherd J, Gaw A \& Sattar N 2001 Plasma leptin and the risk of cardiovascular disease in the west of Scotland coronary prevention study (WOSCOPS). Circulation 104 3052-3056. (https://doi.org/10.1161/ hc5001.101061)

Wallerstedt SM, Eriksson AL, Niklason A, Ohlsson C \& Hedner T 2004 Serum leptin and myocardial infarction in hypertension. Blood Pressure 13 243-246. (https://doi.org/10.1080/08037050410021405)

Yang R \& Barouch LA 2007 Leptin signaling and obesity: cardiovascular consequences. Circulation Research 101 545-559. (https://doi. org/10.1161/CIRCRESAHA.107.156596)

Yzydorczyk C, Li N, Chehade H, Mosig D, Bidho M, Keshavjee B, Armengaud JB, Nardou K, Siddeek B, Benahmed M, et al. 2017 Transient postnatal overfeeding causes liver stress-induced premature senescence in adult mice. Scientific Reports 7 12911. (https://doi. org/10.1038/s41598-017-11756-2)

Zohdi V, Lim K, Pearson JT \& Black MJ 2014 Developmental programming of cardiovascular disease following intrauterine growth restriction: findings utilising a rat model of maternal protein restriction. Nutrients 7 119-152. (https://doi.org/10.3390/ nu7010119)

Received in final form 23 October 2019

Accepted 29 October 2019

Accepted Manuscript published online 29 October 2019
(C) 2020 Society for Endocrinology Published by Bioscientifica Ltd. 